\title{
O CAÇADOR DE OSSOS
}

Victória Amaro da Rocha ${ }^{1}$

- Enviado em 13/05/2017

- Aprovado em 28/06/2017

O presente texto tem como objetivo apresentar a história do resgate do corpo do Barão do Serro Azul, um importante político e ervateiro para a história do Paraná, bem como destacar o Coronel Luiz Victorino Ordine, outro político de destaque para o estado, o qual realizou e organizou a expedição de resgate do corpo do Barão. Por meio de referências documentais pudemos relatar o acontecimento, fragmentando-o da maneira como foi publicado no jornal Gazeta do Povo. Os relatos são de nove publicações feitas entre os dias 5 e 20 de maio de 1924.

\section{I) LUIZ VICTORINO ORDINE}

O coronel Luiz Victorino Ordine nasceu na Itália no dia 8 de novembro de 1878 . Veio ao Brasil com dezessete anos, a fim de continuar seus estudos. Como a lei italiana obrigava o primogênito a servir o exército e seguir carreira militar e seu irmão mais velho deu seguimento à carreira médica, Ordine foi obrigado a cumprir a lei. (BOBROWEC, 2014, p.12)

1 Estudante do curso de Engenharia Elétrica da Universidade Tecnológica Federal do Paraná. Contato: vrocha@alunos.utfpr.edu.br 


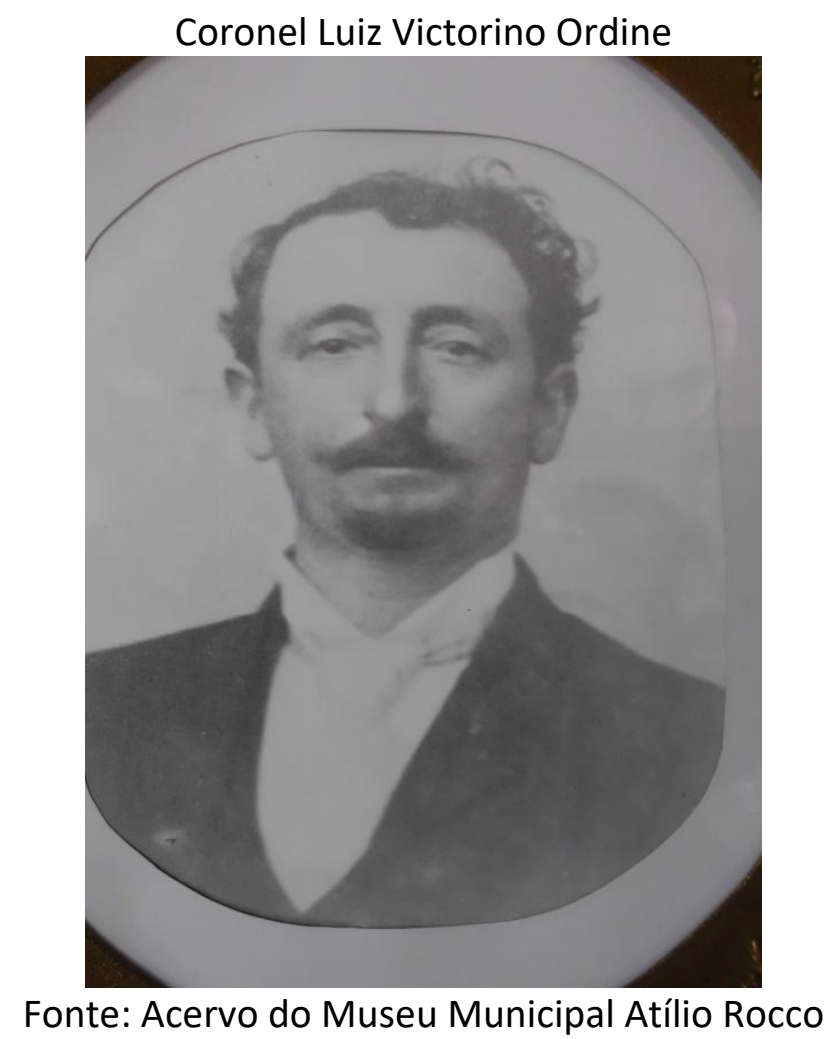

Vindo de família rica, chegou ao Brasil com capital para investir e comprar terras tornandose, assim, influente frente à população local e ganhando o título de coronel da Guarda Nacional. Durante o período, possuir bens e propriedades, bem como laços de afinidade com poderosos, era mais determinante para ser coronel, alferes ou capitão do que o próprio reconhecimento militar. Por isso, Ordine e sua família não seriam os únicos a possuir tais títulos, criando intrigas e inimizades nesse meio. (BOBROWEC, 2014, p.12)

O coronel assumiu, em 1900, o cargo político na prefeitura de São José dos Pinhais, onde permaneceu durante dois mandatos (1900-1904, 1904-1908). Foi o primeiro prefeito eleito do município. Quem o sucedeu politicamente foi justamente seu inimigo político, Francisco de Paula Killian². Killian era são-joseense, militar e também integrante da Guarda Nacional. A rivalidade registrada entre ambos foi emblemática.

Ao assumir o cargo, Killian abre um inquérito para apurar o possível envolvimento de Ordine em desvios de verbas e abusos de autoridade. Este fato fez com que o coronel motivasse o

\footnotetext{
${ }^{2}$ Francisco Killian era funcionário público e exportador atacadista de erva-mate. Além de prefeito em São José dos Pinhais, foi deputado estadual nas legislaturas de 1918-1919 e 1920-1921, pelo Partido Republicano Paranaense. (GOULART, 2014, p. 372).
} 
"caso do extravio dos arquivos da prefeitura municipal", quando deu fim a todos os documentos de seu último mandato, apagando uma importante parte da história da cidade. (BOBROWEC, 2014, p.12)

Mesmo assim, Ordine possuía grande prestígio em São José dos Pinhais. Ainda é lembrado em nome de rua e tendo a casa onde morou como abrigo do museu Municipal Atílio Rocco, na parte central da cidade.

Casa de Luiz Victorino Ordine, já como Museu Municipal no ano de 2012

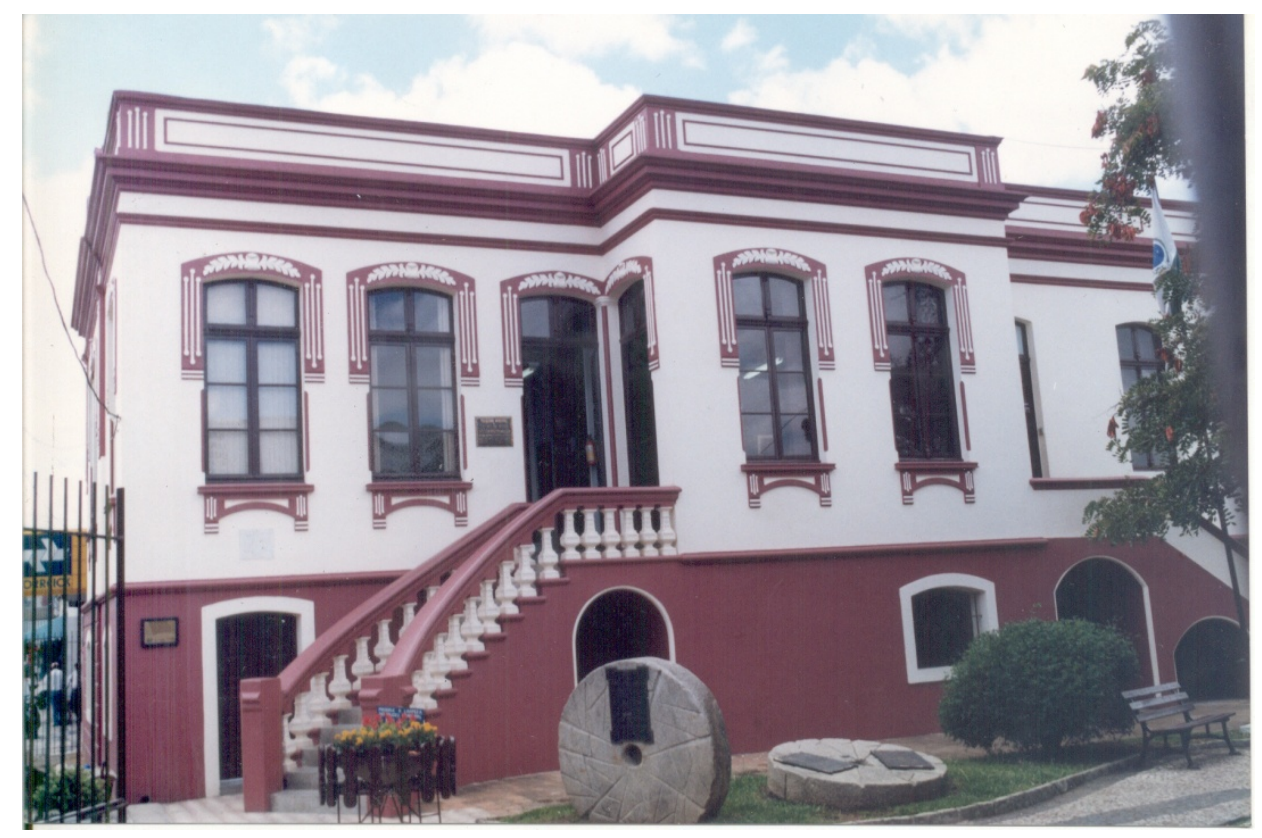

Fonte: Acervo do Museu Municipal Atílio Rocco 
Casa em que o Coronel Luiz Victorino Ordine morava quando residiu em São José dos Pinhais.

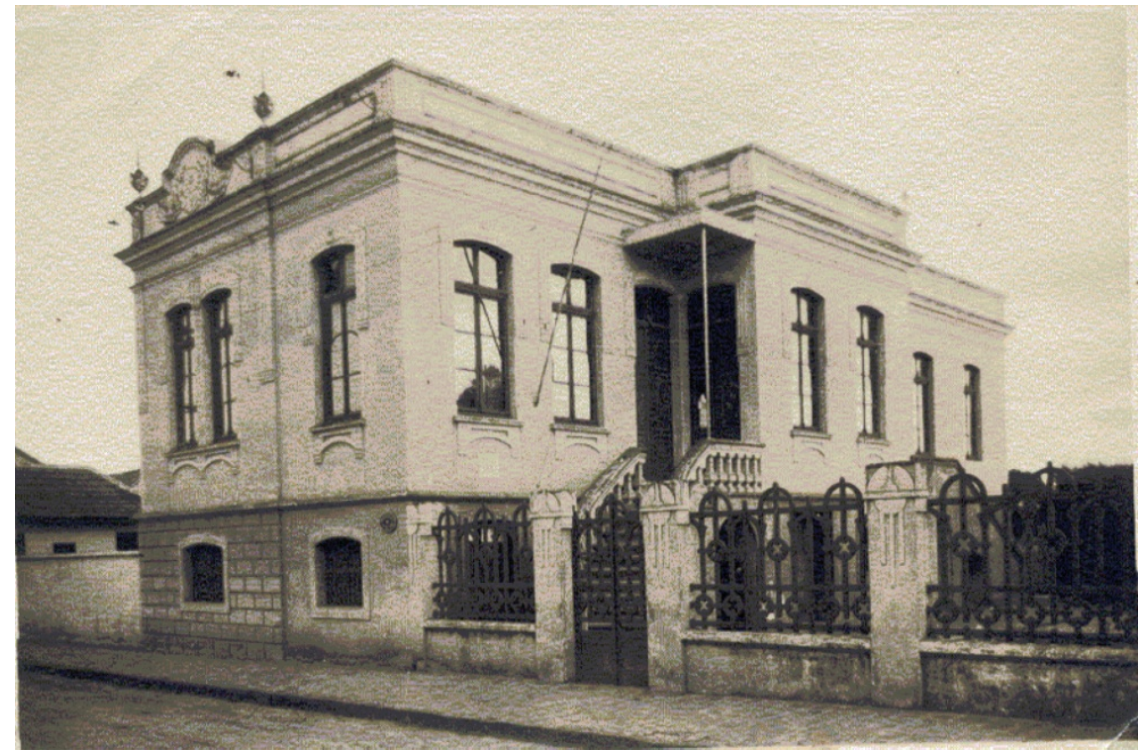

Fonte: Acervo do Museu Municipal Atílio Rocco

\section{II) ILDEFONSO PEREIRA CORREIA}

Nasceu, em Paranaguá, o Barão do Serro Azul, no dia 6 de agosto de 1847. Filho do comendador Manoel Francisco Correia e da Sra. D. Francisca Pereira Correia. Em seus primeiros dezessete anos, o Barão se dedicou à carreira de letras, e depois realizou um curso superior na área. Mas por decisão dos pais seguiu na área do comércio, e foi estudar em Montevidéu e depois em Buenos Aires. (POMBO,1980)

Em 1872, o Barão expande seus negócios e atividades industriais na área ervateira. Fundou uma importante casa do comércio em Antonina, com o retorno dessa conseguiu fixar residência em Curitiba. Na capital fundou outras casas responsáveis por grande parte de sua fortuna. (POMBO, 1980)

O Barão do Serro Azul foi um importante ervateiro do Paraná, reconhecido inclusive com a medalha do "Mérito Agrícola". O estabelecimento mais importante de Curitiba que ele fundou foi 
referência para os demais produtores, pela maneira inovadora de preparo, mais rápida, e pela diferenciada forma de embalar os produtos. (POMBO, 1980)

Teve participação na arquitetura, literatura e política do estado do Paraná. Participou da obra da igreja Matriz (hoje catedral) de Curitiba. Escrevia constantemente, com estilo "simples e correto". Em 1882 assumiu como deputado provincial e em 1887 foi designado terceiro vice presidente da Província. Já em 1888, com a renúncia do presidente, assumiu o cargo de presidente provisório do dia 30 de junho de 1888 ao dia 4 de julho do mesmo ano. Recebeu o título de Barão, dado pela princesa Isabel, em 8 de agosto de 1888. Foi também presidente da câmara municipal de Curitiba e fundador da Associação Comercial do Paraná, fundada em 1890. Morreu, durante a Revolução Federalista ${ }^{3}$, porque teria sido acusado de traição quando levantou dinheiro para as tropas federalistas não usarem de violência em Curitiba, como faziam em todo os lugares que passavam. (POMBO, 1980; CESAR, 2017)

\section{III) A TRAGÉDIA DO PICO DO DIABO}

Em 1924, o Jornal Gazeta do Povo publicou, em fascículos, a história do resgate do corpo do Barão do Serro Azul, 30 anos após a sua morte. O resgate ocorreu passado um ano do falecimento, tempo que a viúva do Barão esperou para dar um enterro digno ao marido. Na época da Revolução Federalista o Barão foi considerado traidor, como dito acima, e depois da sua morte nem seu nome podia ser comentado, quanto mais realizar um enterro em sua memória.

As publicações ${ }^{4}$ foram classificadas como episódios inéditos sobre a revolução de 94, quando foram fuzilados cinco renomados paranaenses ${ }^{5}$, a caminho da Serra do Mar. O relato é feito pelo próprio Luiz Victorino Ordine, responsável pelo resgate e amigo próximo do Barão.

\footnotetext{
${ }^{3}$ A Revolução Federalista foi um conflito de cunho político que se desencadeou em entre os anos de 1893 a 1895 . A revolta armada ocorreu no Rio Grande do Sul, mas atingiu também o Paraná e Santa Catarina (CARONE, 1970).

${ }^{4} \mathrm{O}$ referido material faz parte do acervo de fotos da professora Mônica Helena Harrich Silva Goulart, registos realizados durante sua pesquisa de doutorado, na Biblioteca do Museu Paranaense. O Jornal Gazeta do Povo também possui em seus acervos as referidas publicações (MILAN, 2010).

${ }^{5}$ Barão do Serro Azul, Presciliano da Silva Correa, José Lourenço Schleder, José Joaquim Ferreira de Moura e Balbino Carneiro de Mendonça. Nessa parte do relato não é citado o nome de outro fuzilado, Lourenço Rodrigo de Matos Guedes, mas a participação deste é confirmada no comentário da Gazeta do Povo do dia 13 de maio de 1924
} 
A história, assim como as publicações, também foi dividida em tópicos:

1. Gazeta do Povo (Segunda-feira, 5 de maio de 1924). Ordine lamenta muito a morte do amigo, por sua parte e de todos os paranaenses. Relatando o resgate como um romance, fazendo do Barão um homem de muitas qualidades e um verdadeiro herói.

2. Gazeta do Povo (Quarta-feira, 7 de maio de 1924). A narrativa, de fato, começa com o relato do dia 5 maio de 1895, um ano após as mortes. Quando as famílias do Barão do Serro Azul e de Presciliano Corrêa, um dos outros cinco fuzilados com o Barão, recorrem ao Coronel Victorino para resgatar o corpo dos falecidos a fim de proporcionar-lhes um enterro digno. O Sr. David Carneiro seguiu junto a Ordine, a mando da esposa do Barão, para falar com o chefe de Polícia do Estado e o General Comandante do então Distrito Militar sobre os assassinatos. Nada encontraram relatando o episódio, mas mesmo assim foram autorizados a realizarem o resgate, desde que o fizessem sem alarde. Falaram com o dono da Estrada de Ferro, e conseguiram vagões para o transporte deles e dos corpos. Com tudo arranjado, o resgate foi interrompido pelo proprietário das terras onde os corpos estavam enterrados, que não admitiu que fossem retirados quaisquer cadáveres sepultados em sua propriedade. Ambos então recuaram e Ordine voltou para São José dos Pinhais a fim de organizar a expedição para roubar os corpos.

3. Gazeta do Povo (Quinta-feira, 8 de maio de 1924). De volta a São José dos Pinhais, Ordine recrutou Joaquim Franco para abrir o caminho na mata que os levasse até os cadáveres, mas devido a uma picada de cobra ele faleceu sem completar o serviço. A família de Joaquim procurou o Coronel para honrar a palavra do pai, dizendo que os filhos terminariam o que o pai havia começado.

4. Gazeta do Povo (Terça-feira, 13 de maio de 1924). Nessa publicação o relato da história é interrompido e mostra-se um documento sobre a verificação da existência dos corpos. Nele há o relato dos homens que foram realizar a tarefa, que são: Capitão Luiz Victorino Ordine, Tenente Agnello Carmeliano Pereira, Alberto Munhoz da Rocha, Domingos Leal Nunes, Manoel Simões e Simão Marques. Sendo os três últimos contratados. Eles então encontraram os 
cadáveres e reconheceram os amigos e conhecidos, que eram: Barão do Serro Azul, Presciliano da Silva Correa, José Lourenço Schleder, José Joaquim Ferreira de Moura e Balbino Carneiro de Mendonça (nas publicações o nome não é contemplado, mas Lourenco Rodrigo de Matos Guedes também foi um dentre o fuzilados). Notaram que os corpos foram removidos do lugar original e que inclusive foram-Ihe levados as joias, acessórios e roupas. O corpo do Barão tinha vestígios de dois tiros; um na parte da frente da coxa direita, e outro em um dos olhos. O de Lourenço estava mais afastado, sem o chapéu e um dos calçados, indício de sua tentativa de fuga. Os cadáveres foram enterrados próximos ao caminho do despenhadeiro. Para registrar o ocorrido, foram lavrados três termos iguais e devidamente assinados em 25 de maio de 1894 .

5. Gazeta do Povo (Quinta-feira, 15 de maio de 1924). Quando o filho de Joaquim Franco avisou Ordine que o trabalho fora cumprido, o Coronel começou a organizar a expedição. Reuniu dez homens, contando ele e o amigo Pedro Falce. Começaram a caminhada, e antes de chegarem ao local pararam para dormir algumas vezes, em casa de amigos e acampamentos. Com medo de que os trabalhadores da estrada de ferro desconfiassem, um dos companheiros foi deixado com os doentes. A certa altura do trajeto, num precipício, dois integrantes do grupo não quiseram prosseguir devido ao perigo do caminho. Então, sobravam cinco para realizar o resgate. Chegaram ao local a noite e não encontraram dificuldades para desenterrar os dois mortos. Passaram o resto da noite nas proximidades e retomaram o caminho ao amanhecer.

6. Gazeta do Povo (Sexta-feira, 16 de maio de 1924). Devido a dificuldade em carregar os corpos, decidiram por levar o corpo do Barão primeiro, e depois os filhos de Joaquim Franco voltariam para buscar o do Sr. Presciliano. Colocaram o cadáver numa rede, e revezando de dois em dois o levaram até David e Leão, seguindo à Roseira para colocar no caixão em seguida para casa do Coronel Ordine. Mas, por descuido, deixaram as sepulturas abertas e um empregado da Estrada de Ferro viu e reconheceu o corpo, denunciando às autoridades. Chamaram o Coronel, já sabendo que ele era o responsável, mas este mentiu e disse que havia os enterrado no cemitério de São José dos Pinhais. Então, combinou com o sr. David Carneiro para que ele o esperasse no Xaxim quando chegassem com os corpos, e mandaria uma carta para avisar, contendo o seguinte: "Segue erva, apronte, sacos.". Quando chegaram com o cadáver de Presciliano, Victorino contratou uma carroça para levar os corpos nos caixões até o sr. 
Carneiro. Estando os caixões devidamente disfarçados para ninguém identificar. O coronel permaneceu na casa de Carneiro até o anoitecer para irem ao cemitério Municipal de Curitiba enterrar os amigos. Após isso, Ordine expõe o acontecimento por meio do termo abaixo:

Termo de inhumação

Aos quinze dias do mez de Maio de mil oitocentos e noventa e cinco, nesta cidade de Cutityba no Cemiteprio plublico effectuou-se dasdelinamente as sete horas da noite o enterramento dos cofres do Barão do Serro Azul (Idenfonso Pereira Correia) e do Commendador Presciliano da Silva Correia, victimas sacrificadas do furor das autoridades legaes a vinte de Maio de mil oitocentos e noventa e quatro, sendo o primeiro inhumado na carneira numero quatro mil quinhentos e quarenta e tres e o segundo na de numero quatro mil quinhentos e cincuenta e dois, achando-se a este acto presentes o desembargador Agostinho Ermelino de Leão, Tenente Coronle Joaquim Antonio Guimarães, David Antonio da Silva Carneiro, Manoel do Rosario Correia, Majores Mauricio Sink e Praxedes Gonçalves Pereira, Doutor Antonio Candido de Leão, Tenente Agostinho Ermelino de Leão Jr. Capitão Luiz Victorino Ordine, José Francisco Corrêa, Leocadio Cysneiro Correia, Pedro Falce, Manoel Xavier Pereira e o zelador do cemiterio Seraphim Santoni; e do que para constar lavro este termo que vae pelos presentes assignados. Eu, Ermelino Agostinho de Leão, servindo de escrivão o escrevi em triplicata. Sellada com estampilha de Aureis, da Republica Brasileira Estado do Paraná.

Agostinho E. de Leão - Dabid A. Carneiro - Luiz Victorino Ordine - Praxedes Gonçalves Pereira - Agostinho E. Leão Junior - Manoel Xavier Pereira José Francisco Correia - Joaquim A.Guimarães - Leocadio Cysneiro Correia - Manoel do Rosario Correia - Dr. Antonio Candido de Leão - Major Mauricio Sink - Pedro Falce e o zelador do cemiterio, Seraphim Santoni.

Aqui termina o relato do Coronel Ordine, e nas publicações seguintes quem conta sua versão é o escrivão, Ermelino de Leão, filho de Agostinho Ermelino de Leão e sobrinho do Barão.

7. Gazeta do Povo (Sábado, 17 de maio de 1924)

8. Gazeta do Povo (Segunda-feira, 19 de maio de 1924)

9. Gazeta do Povo (Terça-feira, 20 de maio de 1924)

Ermelino conta nas datas dos dias 17, 19 e 20 que logo depois das mortes os familiares já queriam levar os corpos ao cemitério São Francisco de Paula, uns queriam, inclusive, realizar uma cerimônia, mas ele reconhece que as "circunstâncias do momento" impossibilitaram essa opção. 
Chegado os restos mortais do Barão, sua esposa e amigos puderam realizar dignamente seu enterro, ainda que no silêncio e longe dos inimigos de Ildefonso Pereira Correia, o Barão do Serro Azul.

\section{IV) CONSIDERAÇÕES FINAIS}

De uma maneira geral, a cultura paranaense é marginalizada em um contexto nacional. A dificuldade em localizar a literatura e história regional se deve à ausência de características marcantes que definam o próprio estado. Bento Munhoz da Rocha Neto reproduziu em livro o que a revista carioca "A Ordem" escreveu:

O Paraná é um Estado típico desses que não têm um traço que faça deles alguma coisa notável, nem geograficamente como a Amazônia, nem pitorescamente como a Bahia ou o Rio Grande do Sul. Sem uma linha vigorosa de história como São Paulo, Minas e Pernambuco, sem uma natureza característica como o Nordeste, sem lendas de primitivismo como o Mato Grosso e Goiás. Por isso o Paraná forma nessa retaguarda característica de incaracterísticos. (NETO, 1995)

Por esse motivo, evidencia-se a dificuldade em encontrar certos registros da história paranaense. Há poucos documentos e fontes que tratam da trajetória de Luiz Victorino Ordine em busca dos ossos do Barão do Serro Azul. No âmbito estadual já é excessivamente complicado buscar referências e, na cidade de São José dos Pinhais, essa dificuldade se acentua, uma vez que os aspectos locais são ainda menos valorizados.

\section{V) REFERÊNCIAS:}


A TRAGÉDIA do Pico do Diabo. Gazeta do Povo, Curitiba, 5 maio 1924, p. 5.

A TRAGÉDIA do Pico do Diabo. Gazeta do Povo, Curitiba, 7 maio 1924, p. 5.

A TRAGÉDIA do Pico do Diabo. Gazeta do Povo, Curitiba, 8 maio 1924.

A TRAGÉDIA do Pico do Diabo. Gazeta do Povo, Curitiba, 13 maio 1924, p.5.

A TRAGÉDIA do Pico do Diabo. Gazeta do Povo, Curitiba, 15 maio 1924.

A TRAGÉDIA do Pico do Diabo. Gazeta do Povo, Curitiba, 16 maio 1924.

A TRAGÉDIA da Serra. Gazeta do Povo, Curitiba, 17 maio 1924, p. 5.

A REVOLUÇÃO de 93. Gazeta do Povo, Curitiba, 19 maio 1924.

A TRAGÉDIA da Serra. Gazeta do Povo, Curitiba, 20 maio 1924, p. 5.

BOBROWEC, Antonio. Almanaque São José dos Pinhais. Revista Pública, Ano IV, n.7, v.1, 2014.

BOBROWEC, Antonio. Luiz Victorino Ordine. Revista Correio, São José dos Pinhais, n.866, 2014.

CARONE, E. República Velha, São Paulo, 1970.

CESAR, L. Revolução Federalista - Barão do Serro Azul mantém a paz e a ordem em Curitiba. Disponível em: <http://www.chasquedoconhaque.com.br/chasque/?p=4554>. Acesso em: 17 jan. 2017.

GOULART, Mônica Helena H. S. A Dança das Cadeiras: análise do jogo político na Assembleia Legislativa do Paraná (1889-1930).

MILAN, Polliana. Os ossos do Barão. Gazeta do Povo, Curitiba,27 ago. 2010. Disponível em: <http://www.gazetadopovo.com.br/vida-e-cidadania/os-ossos-do-barao-

2j14s434yixvu0xwh28jgko5q>. Acesso em: 03 dez. 2016.

NETO, B. M. R. O Paraná, ensaios. Curitiba: Coleção Farol do Saber, 1995.

POMBO, José Francisco da Rocha. Para a história: notas sobre a invasão federalista no Estado do Paraná. Curitiba: Fundação Cultural de Curitiba, 1980.

REZENDE, C. J. (Org.) Paraná espaço e memória: diversos olhares histórico-geográficos. Curitiba: Editora Bagozzi, 2005.

ZATTI, C. Literatura paranaense: provocações. Disponível em: <http://www.protexto.com.br/texto.php?cod_texto=210>. Acesso em: 03 dez. 2016. 